Elsevier Editorial System(tm) for CARBON Manuscript Draft

Manuscript Number:

Title: Negative thermoelectric power of melt mixed vapor grown carbon nanofibers polypropylene composites

Article Type: Research Paper

Corresponding Author: Dr. Antonio J. Paleo,

Corresponding Author's Institution:

First Author: Antonio J. Paleo

Order of Authors: Antonio J. Paleo; Eliana M. F. Vieira; Kening Wan; Oleksandr Bondarchuk; Maria F. Cerqueira; Luis M. Gonçalves; Emiliano Bilotti; Pedro Alpuim; Ana M. Rocha

Abstract: In this work, commercial vapor grown carbon nanofibers (CNF), produced by chemical vapor deposition (CVD), were melt extruded with polypropylene (PP) with the aim of analyzing their thermoelectric properties (i.e., electrical conductivity, thermoelectric power, power factor and figure of merit). Unexpectedly, all PP/CNF composites, instead of showing the typical positive thermoelectric powers (TEP) observed for this type of carbon-based polymer composites, they showed negative TEP values.These results can be attributed to the double layer structure surrounding the tubular core of the carbon nanofiber grown by the CVD method at $1100{ }^{\circ} \mathrm{C}$, which may lead to that the intrinsically negative TEP from the inner shells counteract the positive TEP contribution from the outer surface shells of CNF due to oxygen doping. Overall, all composites showed negative TEP values around -8.5 $\mu \mathrm{VK}-1$, and a maximum power factor of $1.75 \times 10-3 \mu \mathrm{W}$ m-1 K-2, corresponding to a figure of merit of $4 \times 10-$ 9. This study demonstrates that melt mixed polymer composites with largediameter tubular carbon nanostructures and negative seebeck coefficients can be directly produced with large-scale processing methods without requiring specific additives and/or deoxygenation treatments.

Suggested Reviewers: Milo Shaffer

m.shafferdimperial.ac.uk

Jaime C. Grunlan

jgrunlanetamu.edu

Klaus Rademann

klaus.rademann@chemie.hu-berlin. de

Opposed Reviewers: 
Dear Editor Ph. D. Gareth B Neighbour,

Please, this work is a fresh version of a manuscript recently submitted. In our previous submission, the revised manuscript, after including some points of the work corrected from the comments sent by the reviewers, was finally rejected. Nevertheless, your final positive words in your letter saying that you would be happy to re-review a fresh version of the paper, it encouraged us to re-submit again this new and fresh version. The main core of the paper is untouched, but some alterations were made in the FTIR and XPS sections after very carefully checking.

We honestly consider that this fresh version, which includes and discusses all the principal corrections pointed out by the previous three referees of the first submission, it is now a more complete and valuable work, and therefore, we insist in firmly believe that Carbon is the most appropriate journal to disseminate our work.

With kind regards,

Antonio J. Paleo 


\section{Negative thermoelectric power of melt mixed vapor grown carbon nanofibers polypropylene composites}

\section{A. J. Paleo,", E. M. F. Vieira ${ }^{2}$, K. Wan $^{3}$, O. Bondarchuk ${ }^{4}$, M. F. Cerqueira ${ }^{4,5}$, L. M. Goncalves $^{2}$, E. Bilotti ${ }^{3}$, P. Alpuim ${ }^{4,5}$, A. M. Rocha ${ }^{1}$}

12C2T-Centre for Textile Science and Technology, Department of Textile Engineering University of Minho, Campus de Azurém, 4800-058 Guimarães, Portugal

${ }^{2}$ CMEMS-UMinho-Center for MicroElectromechanical Systems, University of Minho, Campus de Azurém, 4800-058 Guimarães, Portugal

${ }^{3}$ SEMS-School of Engineering and Material Sciences, Queen Mary University of London, Mile End Road, London, United Kingdom

${ }^{4}$ INL-International Iberian Nanotechnology Laboratory, Av. Mestre. Jose Veiga, Braga, Portugal

${ }^{5}$ CFUM - Center of Physics of the University of Minho, Campus de Gualtar, 4710-057 Braga, Portugal

* Corresponding author:

E-mail address: ajpaleovieito@2c2t.uminho.pt (A. J. Paleo) 


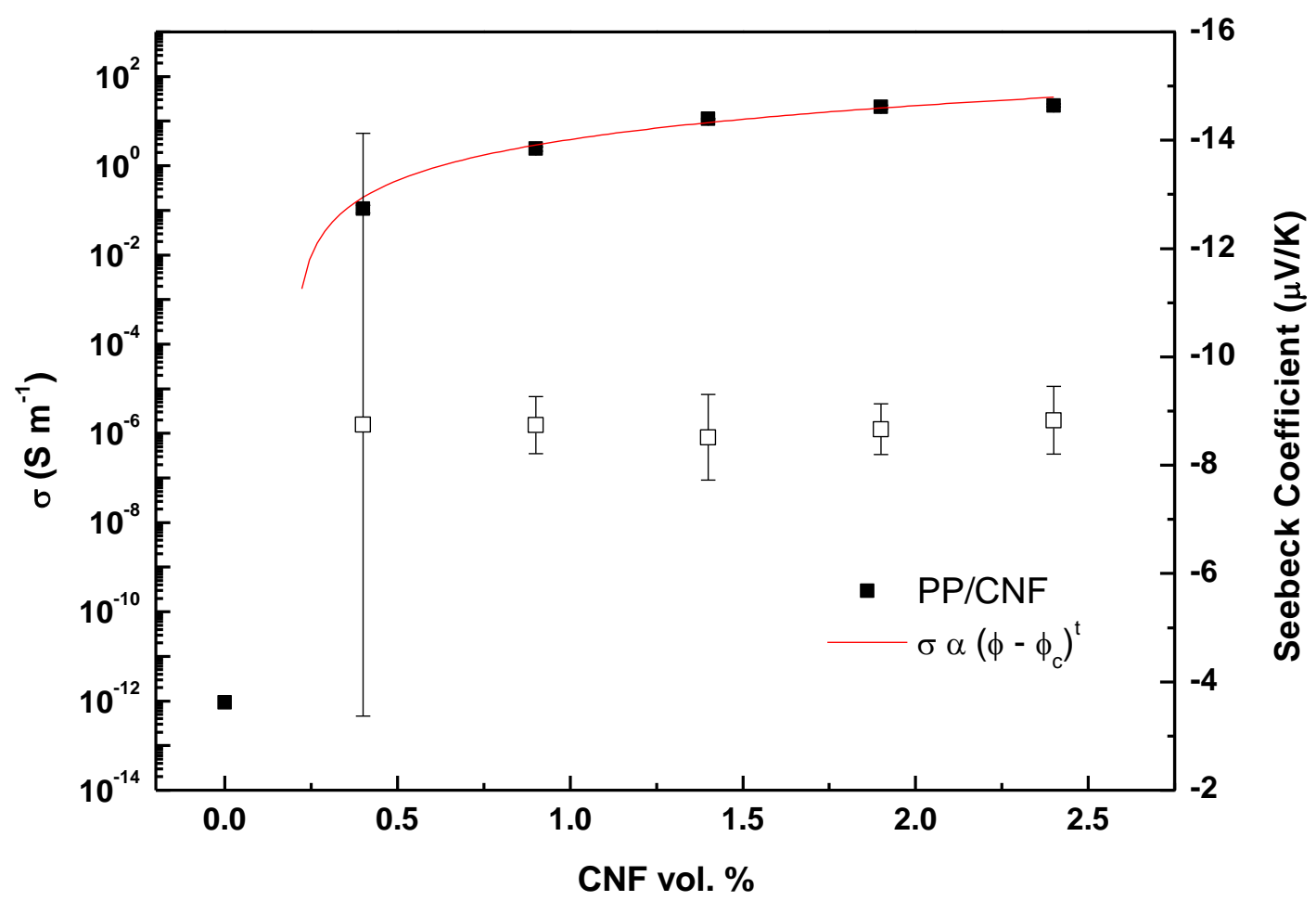

Electrical conductivity (solid symbols), power law fitting, and negative Seebeck coefficient (open symbols) as function of CNF content in PP/CNF composites 


\title{
Negative thermoelectric power of melt mixed vapor grown carbon nanofibers polypropylene composites
}

\section{A. J. Paleo ${ }^{1, *}$, E. M. F. Vieira ${ }^{2}$, K. Wan $^{3}$, O. Bondarchuk ${ }^{4}$, M. F. Cerqueira ${ }^{4,5}$, L. M. Goncalves $^{2}$, E. Bilotti ${ }^{3}$, P. Alpuim ${ }^{4,5}$, A. M. Rocha ${ }^{1}$}

\author{
${ }^{1}$ 2C2T-Centre for Textile Science and Technology, Department of Textile Engineering \\ University of Minho, Campus de Azurém, 4800-058 Guimarães, Portugal \\ ${ }^{2}$ CMEMS-UMinho-Center for MicroElectromechanical Systems, University of Minho, \\ Campus de Azurém, 4800-058 Guimarães, Portugal \\ ${ }^{3}$ SEMS-School of Engineering and Material Sciences, Queen Mary University of London, \\ Mile End Road, London, United Kingdom \\ ${ }^{4}$ INL-International Iberian Nanotechnology Laboratory, Av. Mestre. Jose Veiga, Braga, \\ Portugal \\ ${ }^{5}$ CFUM - Center of Physics of the University of Minho, Campus de Gualtar, 4710-057 \\ Braga, Portugal \\ * Corresponding author: \\ E-mail address: ajpaleovieito@ 2c2t.uminho.pt (A. J. Paleo)
}




\begin{abstract}
In this work, commercial vapor grown carbon nanofibers (CNF), produced by chemical vapor deposition (CVD), were melt extruded with polypropylene (PP) with the aim of analyzing their thermoelectric properties (i.e., electrical conductivity, thermoelectric power, power factor and figure of merit). Unexpectedly, all PP/CNF composites, instead of showing the typical positive thermoelectric powers (TEP) observed for this type of carbonbased polymer composites, they showed negative TEP values. These results can be attributed to the double layer structure surrounding the tubular core of the carbon nanofiber grown by the CVD method at $1100{ }^{\circ} \mathrm{C}$, which may lead to that the intrinsically negative TEP from the inner shells counteract the positive TEP contribution from the outer surface shells of CNF due to oxygen doping. Overall, all composites showed negative TEP values around $-8.5 \mu \mathrm{VK}^{-1}$, and a maximum power factor of $1.75 \times 10^{-3} \mu \mathrm{W} \mathrm{m} \mathrm{m}^{-1}$, corresponding to a figure of merit of $4 \times 10^{-9}$. This study demonstrates that melt mixed polymer composites with large-diameter tubular carbon nanostructures and negative Seebeck coefficients can be directly produced with large-scale processing methods without requiring specific additives and/or deoxygenation treatments.
\end{abstract}

\title{
1. Introduction
}


Thermoelectric (TE) materials are a kind of energy harvesting materials that are able to transform a temperature gradient into an electrical voltage, calculated by $\alpha=\frac{\Delta V}{\Delta T}$, named as Seebeck coefficient $(\alpha)$ or thermoelectric power (TEP). The TEP can be positive or negative depending on the charge carrier majority type [1]. In p-type TE materials (positive $\alpha$ ) there is a dominant hole conduction, whereas in n-type TE materials (negative $\alpha$ ) the majority carriers are electrons [2,3]. Independently of the Seebeck coefficient sign, the efficiency of a TE material is evaluated by its dimensionless figure of merit $z T=\frac{\alpha^{2} \sigma}{k} T$, where $\sigma$ is the electrical conductivity, $k$ is the thermal conductivity and $T$ is the absolute temperature [4]. A TE material can also be evaluated by its power factor (PF) defined as $P F=\alpha^{2} \sigma$, when the data for $k$ is not available. According to the figure of merit, the best TE materials should have high $\sigma$ and $\alpha$, to deliver high PF, and low thermal conductivity. Nevertheless, the complex intercorrelation between these three parameters $(\sigma, \alpha$ and $\mathrm{k})$, together with the fact that they do not have the same dependence on carrier density [2], make difficult to produce TE materials with the highest efficiency. Currently, inorganic semiconductors like bismuth telluride $\left(\mathrm{Bi}_{2} \mathrm{Te}_{3}\right)$, with zT around 1 , are the most commonly used TE materials [3]. However, the combination of their high thermal conductivities together with the scarcity and toxicity of their elements (particularly tellurium), brittleness and high cost have increased the interest in investigating different type of TE materials [5]. It is in this scenario that carbon nanostructures, such as carbon nanotubes (CNT), acquire high relevance thanks to their excellent electrical, thermal and mechanical properties [6], together with their approximately seven times lower density $\left(1 \mathrm{~g} / \mathrm{cm}^{3}\right)$ than $\mathrm{Bi}_{2} \mathrm{Te}_{3}(7.7$ $\mathrm{g} / \mathrm{cm}^{3}$ ). In this way, CNT have great potential for use in many flexible and wearable TE applications. In particular, the investigation of CNT as TE emerging materials has grown considerably due to their good intrinsic thermoelectric power and their possibility for doping by physical/chemical methods to tune their $\alpha$ [7]. However, one important drawback of CNT is that they have shown high thermal conductivities $(k \sim 2000 \mathrm{~W} / \mathrm{mK})$ [8], which reduce drastically their figure of merit. In this regard, conductive polymer composites (CPC) consisting of insulating/conducting polymers and CNT, have emerged as a new source of TE materials due to the good balance provided by the good $\sigma$ and $\alpha$ from CNT, and the low $k$ provided by the polymer [9]. On the other hand, when choosing the type of 
CNT for producing CPC composites with the desired properties, it is important to distinguish first their intrinsic TE properties, which may vary depending on the processing methods used. For instance, most as-produced CNT are p-type due to their inherent oxygenation after processing [10], though some rare exceptions were reported where the high growth temperatures in multiwalled carbon nanotubes (MWCNT) produced by chemical vapor deposition (CVD), has switched them from $\mathrm{p}$ to $\mathrm{n}$-type above a certain threshold temperature [11]. Consequently, most of reported works on CPC with CNT are ptype TE materials, and the reader is referred to recent revisions on CPC based on insulating/conducting polymers with $\mathrm{CNT}[2,12]$.

Despite the huge interest in polymer/CNT composites as novel TE materials above commented, very limited research has been focused on studying the TE properties of a different type of carbon nanostructure known as carbon nanofibers (CNF), which are similar to carbon nanotubes but show different physical and chemical properties because of their larger diameters and less perfect outer layers with a range of angles related to their graphitic tubular core [13]. Among the very few works focused on the analysis of TE properties of $\mathrm{CNF}$, the authors have found a single study where self-organized macroscopic solid structures consisting of CNF grown by means of methane pyrolysis in the presence of $\mathrm{NiO}$ as a catalyst, showed a negative Seebeck coefficient of $-11 \mu \mathrm{VK}^{-1}$ [14]. More recently, solution mixed polymer composites of ethylene-octene copolymer (ECO) and CNF were reported with positives TEP of $14 \mu \mathrm{VK}^{-1}$ [15]. In this regard, the first aim of this work is to fill the existing lack of studies focused on the thermoelectric properties (i.e. TEP, PF and zT) of conducting polymer composites based on CNF. For this purpose, a conventional polypropylene (PP) with commercial vapor grown carbon nanofibers, synthesized by CVD, was selected to produce conducting polymer composites by melt mixing. Quite unexpectedly, we found that our composites, instead of behaving as p-type TE materials as most of reported works on CPC with CNT, they showed n-type behavior due to the intrinsic n-type nature of CNF used in this work. As far as the authors are aware, this is the first work reporting n-type TE conducting polymer composites directly obtained by mixing a conventional insulating polymer and as-produced carbon nanostructures (including 
carbon nanotubes, graphene and their derivatives) without using either a pre-treatment for functionalization/doping of CNF or additional additives during processing.

\section{Experimental}

\subsection{Materials}

A polypropylene powder, Borealis EE002AE, was used as polymer matrix and vapor grown carbon nanofibers, Pyrograf®-III PR 24 LHT XT, (ASI, Cedarville, OH, USA), were selected for producing melt mixed polypropylene-based composites with electrical conducting properties. The PR 24 LHT XT fibers, with diameters of around $125 \mathrm{~nm}$, have shown two different structural layers with diameters of around $30 \mathrm{~nm}$ in total surrounding the tubular structure (Figure 1) [16]. This type of CNF has shown lengths ranging from 50 to $100 \mu \mathrm{m}$ with thermal conductivities around $2000 \mathrm{~W} / \mathrm{mK}$ [17].

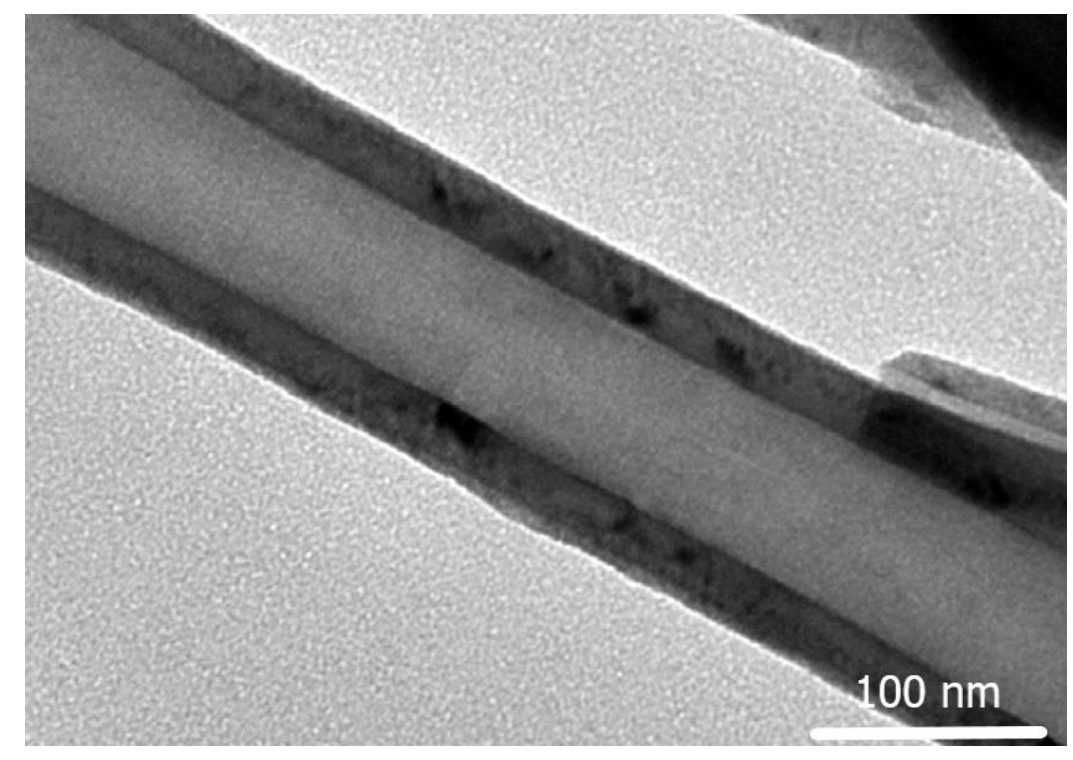

Fig. 1. TEM micrograph of Pyrograf®-III PR 24 LHT XT vapor grown carbon nanofiber

\subsection{Polymer composites processing}

Melt mixed PP/CNF composites were fabricated on a modular lab-scale intermeshing minico-rotating twin-screw extruder, with a screw diameter of $13 \mathrm{~mm}$, barrel length of $31 \mathrm{~cm}$ and an approximate L/D ratio of 26, coupled to a cylindrical rod dye of approximate 2.85 mm diameter. A detailed description of the melt extrusion conditions has been previously published [18]. The extruded PP/CNF composites were then pelletized and pressed into 
compression-molded specimens with the appropriate geometries for electrical and thermoelectric measurements. PP/CNF composites with five different CNF concentrations 0.4 vol \% (equivalent to $1 \% \mathrm{wt}$ ), 0.9 vol \% (2\% wt), 1.4 vol \% (3\% wt), 1.9 vol \% (4\% wt) and 2.4 vol \% (5\% wt), were prepared.

\subsection{Morphological characterization}

Morphological analysis was realized in an ultra-high resolution Field Emission Gun Scanning Electron Microscopy (FEG-SEM), NOVA 200 Nano SEM, FEI Company. Secondary electron images to analyze the topography of samples were performed with an acceleration voltage of $10 \mathrm{kV}$. The samples were broken under cryogenic conditions (liquid nitrogen) and then sputter-coated with a very thin film (1 nm) of Au-Pd (80-20 weight \%) before testing. An analytical TEM (JEOL JEM 1010) was used to observe the morphology of CNF. Fiber samples was dispersed in isopropanol and a drop was placed in a grid for direct observation.

\subsection{Structural characterization}

Infrared spectroscopy measurements (FTIR) were performed with Vertex 80v (Bruker) in attenuated total reflection (ATR) mode from 4000 to $650 \mathrm{~cm}^{-1}$. The experimental ATR spectra was converted to transmission spectra using OPUS software. The measurements were performed with the samples kept at room temperature in the sample compartment and evacuated down to 4 mbar. FTIR of pristine CNF was obtained in the reflection standard mode of a CNF pastille and then converted to transmission spectra (using the approximation $\mathrm{T}=1-\mathrm{R})$. Raman spectroscopy measurements were carried out on an ALPHA300 R Confocal Raman Microscope (WITec) using $532 \mathrm{~nm}$ laser for excitation in back scattering geometry. The laser beam with $\mathrm{P}=2 \mathrm{~mW}$ was focused on the sample by a $\mathrm{x}$ 50 lens (Zeiss), and the spectra were collected with 600 groove/mm grating using 5 acquisitions with $2 \mathrm{~s}$ acquisition time. The surface characterization was performed by means of X-ray photoelectron spectroscopy (XPS) in the ultra-high vacuum (UHV) system ESCLAB 250Xi (Thermo Fisher Scientific). The base pressure in the system was below $5 \times 10^{-10}$ mbar. The XPS spectra were acquired with a hemispherical analyzer and X-ray source producing monochromated $\mathrm{Al} \mathrm{K \alpha}(\mathrm{h} v=1486.61 \mathrm{eV})$ radiation operated at $15 \mathrm{kV}$, power $300 \mathrm{~W}$ and X-ray beam spot size $0.9 \mathrm{~mm}$. The XPS spectra were recorded with pass 
energies $20 \mathrm{eV}$ and $200 \mathrm{eV}$ for high resolution and survey spectra, respectively. The XPS spectra were peak-fitted using Avantage processing software (Thermo Fisher Scientific). For peak fitting the Lorentzian/Gaussian (30/70\%) line shape and "Smart" background subtraction were used. Quantification has been done using sensitivity factors provided by the Avantage's library.

\subsection{Thermoelectric properties}

Electrical conductivity of composites with CNF concentrations from 0.4 to $2.4 \mathrm{vol} \%$ and PP neat samples of dimensions around $0.6 \mathrm{~mm}$ (thickness) x $15 \mathrm{~mm}$ x $15 \mathrm{~mm}$ were measured using the two-point resistance method composed by a picometer (Keithley 6485) and a DC voltage source (Agilent $6614 \mathrm{C}$ ). The electrical conductivity was calculated by

$\sigma=\frac{l}{R A}$, where $R, l$ and $A$ are the electrical resistance, length and cross-sectional area of the measured specimen, respectively. The final conductivity for each CNF concentration was obtained as the average of four samples. The Seebeck coefficient was measured with an MMR's Seebeck System. PP/CNF films were cut into strips of about $2 \mathrm{~mm} \times 5 \mathrm{~mm}$ and connected by silver paint on the test stage. The environmental temperature was controlled at $300 \mathrm{~K}$ by a $\mathrm{K} 20$ digital temperature controller under nitrogen gas. A stable temperature difference was applied by heating one end of the sample with $25 \mathrm{~mW}$ power for 30 seconds, using SB100 digital Seebeck controller. The temperature difference was measured using a reference constantan wire sample. Average values of Seebeck coefficient were calculated out of 3 specimens and repeated at least 10 times for each specimen.

\section{Results and discussions}

\subsection{Morphological Analysis}

A representative SEM image of individual fibers is shown in Fig. 2a. The SEM micrographs related to PP composites containing $0.4,1.4$ and 2.4 vol. \% CNF are shown in Fig. 2b, $c$ and d, respectively. The micrographs show the increasing amount of CNF without signals of agglomeration. Compared to other grades of Pyrograf®-III, such as PR 25 PS XT, the PR 24 LHT XT grade used in this study has higher aspect ratio, which would explain their better dispersion in the polymer [19]. 

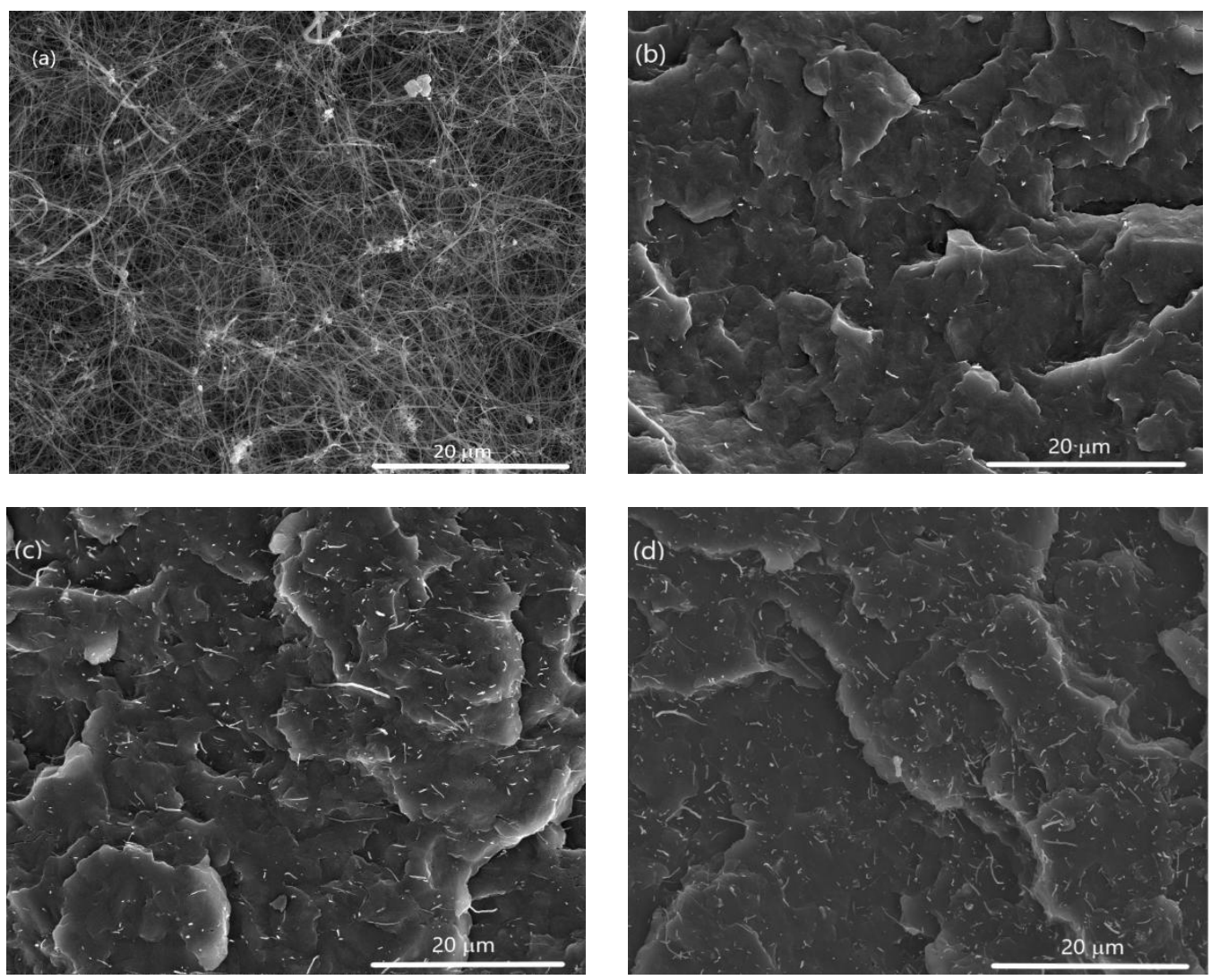

Fig. 2. SEM micrographs of CNF (a) and 0.4 (b), 1.4 (c) and 2.4 vol \% (d) PP/CNF composites

\subsection{Structural analysis}

Infrared spectroscopy is a widely used characterization technique to elucidate the structure and interactions in different materials, including polymer composites. Fig. 3 presents the spectra of PP and CNF in comparison with the PP samples filled with 0.4, 1.4 and 2.4 vol. $\%$ of CNF. Neat PP spectrum shows the characteristic bands assigned to asymmetric and symmetric stretching vibrations of $\mathrm{CH}_{3}$ and $\mathrm{CH}_{2}$ groups in the $3000-2750 \mathrm{~cm}^{-1}$ region and to the $\mathrm{CH}_{3}$ asymmetric and symmetric bending between 1455 and $1375 \mathrm{~cm}^{-1}$ [20]. Other noticeable band is located at $1164 \mathrm{~cm}^{-1}$ assigned to $\mathrm{C}-\mathrm{C}$ stretching, $\mathrm{CH}_{3}$ rocking and $\mathrm{CH}$ bending. The band at $998 \mathrm{~cm}^{-1}$ is assigned to $\mathrm{CH}_{3}$ rocking, $\mathrm{CH}$ bending and $\mathrm{CH}_{2}$ wagging vibration and $973 \mathrm{~cm}^{-1}$ is assigned to $\mathrm{CH}_{3}$ rocking vibration and $\mathrm{C}-\mathrm{C}$ stretching. Finally, the band at $841 \mathrm{~cm}^{-1}$ is assigned to $\mathrm{CH}_{2}$ and $\mathrm{CH}_{3}$ rocking, $\mathrm{C}-\mathrm{C}$ stretching, and $\mathrm{C}-\mathrm{CH}_{3}$ stretching 
vibrations and the band at $809 \mathrm{~cm}^{-1}$ to $\mathrm{C}-\mathrm{C}$ chain symmetric stretching vibration, $\mathrm{CH}_{2}$ rocking vibration and $\mathrm{C}-\mathrm{CH}_{3}$ stretching vibrations $[19,21]$. Pristine $\mathrm{CNF}$ do not show apparently structural information because of the black carbon nanofibers have very high absorbance [22], though intensity bands assigned to $C=C\left(1550 \mathrm{~cm}^{-1}\right.$ and $\left.1210 \mathrm{~cm}^{-1}\right)$ [23], can be observed. It is possible to confirm that the peaks previously described and assigned to the polypropylene remain unchanged after the addition of CNF in $0.4,1.4$ and $2.4 \mathrm{vol}$. \% $\mathrm{PP} / \mathrm{CNF}$ composites, though it is possible to observe a decreasing of their intensity peaks as function of CNF loading. Furthermore, another decreasing of transmittance in the region from 750 to $650 \mathrm{~cm}^{-1}$ is found for PP/CNF composites, thus indicating the contribution from the CNF.

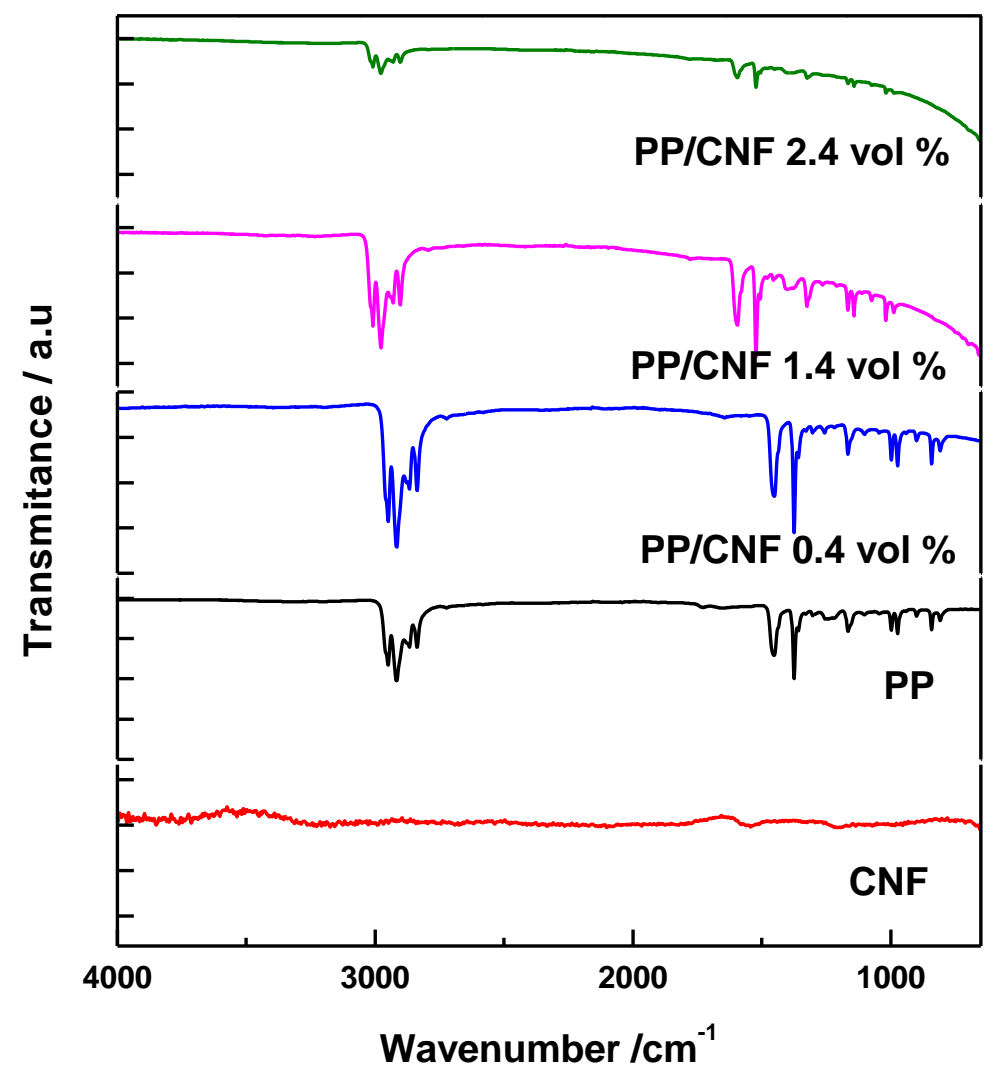

Fig. 3. Infrared spectra of PP, CNF and PP/CNF composites

Fig. 4 shows the Raman spectra of PP, CNF and PP samples filled with 0.4, 1.4 and 2.4 vol. $\%$ of CNF. Neat PP has a rich Raman spectra with modes in the range $80-500 \mathrm{~cm}^{-1}$ [21] and $800-1500 \mathrm{~cm}^{-1}$ [24]. The most intense modes around $3000 \mathrm{~cm}^{-1}$ are assigned to $\mathrm{CH}_{\mathrm{n}}$ 
stretching vibrations [25]. The Raman spectra of pristine CNF presents the signature expected for carbon-based materials with only two Raman bands, the band around $1350 \mathrm{~cm}^{-}$ 1, which is known as the disorder-induced D band [26], and the G-band around $1580 \mathrm{~cm}^{-1}$, characteristic of the graphitic lattice vibration mode [27]. The Raman spectra of composites $\mathrm{PP} / \mathrm{CNF}$, presents the signatures of the two base materials. It is shown that the signature of the PP becomes less intense as the amount of CNF increases in the composites, which is confirmed by the strong decrease observed in the intensity of the PP modes in the $3000 \mathrm{~cm}^{-}$ ${ }^{1}$ range. Simultaneously, the characteristics modes of the CNF are now present for PP/CNF composites. It is noted that the PP mode at $\approx 1500 \mathrm{~cm}^{-1}$, clearly seen in the neat PP spectra, is almost absent when 2.4 vol \% of CNF are incorporated in the PP. Furthermore, the peak position, the full width half maximum of the modes (FWHM) and the intensity ratio were determined by fitting the Raman spectra with Lorentzian functions. The obtained fitting parameters are shown in Table 1 for the G and D modes. The peak positions and FWHM are in agreement with reported data for this kind of material. The intensity ratio between the $D$ and $G$ bands $\left(I_{D} / I_{G}\right)$ can be used for quantifying the disorder in the sample, i.e., it is a measure of the number of disordered $(D)$ to ordered $(G)$ carbon atoms [28]. $\mathrm{I}_{\mathrm{D}} / \mathrm{I}_{\mathrm{G}}$ is close to 1 for pristine CNF (0.91), which confirms the value reported in a previous Raman analysis for the same type of carbon nanofiber [16]. The composites with 0.4 and 1.4 vol \% of CNF also show $\mathrm{I}_{\mathrm{D}} / \mathrm{I}_{\mathrm{G}}$ close to 1 . The lowest $\mathrm{I}_{\mathrm{D}} / \mathrm{I}_{\mathrm{G}}$ obtained for 2.4 vol $\%$ PP/CNF composites (0.77), which corresponds to the highest $\mathrm{La}$, is probably associated with the larger amount of CNF present in the composites, a condition that favors the increase of the crystallite size and consequently decreases the mode associated with the defects (mode D). The in-plane graphitic crystallite size $\left(L_{a}\right)$ was calculated for $\mathrm{CNF}$ and PP/CNF composites by using the following equation: $L_{a}(\mathrm{~nm})=4.4 /\left(\mathrm{I}_{\mathrm{D}} / \mathrm{I}_{\mathrm{G}}\right)$ [29], and results are shown in Table 1 . 


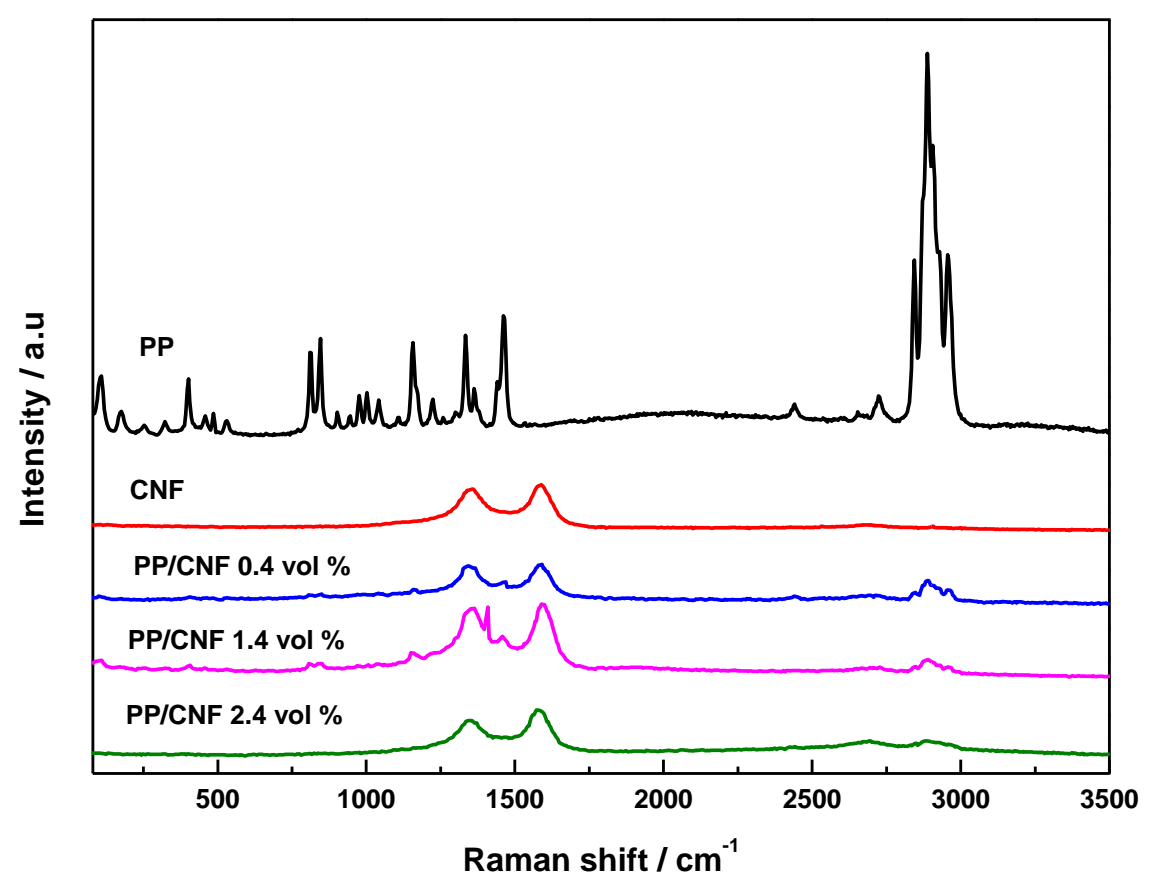

Fig. 4. Raman spectra of PP, CNF and PP/CNF composites

\begin{tabular}{ccccccc} 
Sample & $\omega_{G}\left(\mathbf{c m}^{-1}\right)$ & FWHM $_{G}\left(\mathbf{c m}^{-1}\right)$ & $\omega_{D}\left(\mathbf{c m}^{-1}\right)$ & FWHM $_{\mathbf{D}}\left(\mathbf{c m}^{-1}\right)$ & $I_{D} / \mathbf{I}_{\mathbf{G}}$ & $\mathbf{L}_{\mathbf{a}}(\mathbf{n m})$ \\
\hline CNF & 1586 & 90 & 1352 & 113 & 0.91 & 4.84 \\
PP/CNF 0.4 vol\% & 1586 & 85 & 1345 & 95 & 0.97 & 4.53 \\
PP/CNF 1.4 vol\% & 1593 & 85 & 1353 & 100 & 0.94 & 4.68 \\
PP/CNF 2.4 vol\% & 1580 & 95 & 1349 & 110 & 0.77 & 5.71 \\
\hline
\end{tabular}

Table 1. Parameters obtained from the Raman fitting: $\mathrm{D}$ and $\mathrm{G}$ peak positions, $\omega_{\mathrm{G}}$ and $\omega_{\mathrm{D}}$ respectively $\left(\mathrm{cm}^{-1}\right)$ and respective full width half maximum, $\mathrm{FWHM}_{\mathrm{G}}$ and $\mathrm{FWHM}_{\mathrm{D}}\left(\mathrm{cm}^{-1}\right)$. Intensity ratio between $D$ and $G$ bands $\left(I_{D} / I_{G}\right)$ and in-plane graphitic domain size $\left(L_{a}\right)$ calculated according to [29]

The composition of the CNF, PP and composites filled with $0.4,1.4$ and 2.4 vol \% CNF was assessed by the XPS. Table 2 lists elemental composition of the studied samples. Small amount of oxygen $(\sim 1 \%)$ detected in the $\mathrm{CNF}$ samples can be assigned to $\mathrm{C}-\mathrm{O}$ functional groups present in the carbon nanofibers. Florine, detected in relatively high amount in the $\mathrm{PP}$ and PP/CNF composites, is, probably, due to the interaction between Teflon ${ }^{\circledR}$ sheets used to insulate hot metal plates from hydraulic press and samples during the compression 
mould. Traces of $\mathrm{Si}, \mathrm{N}, \mathrm{Na}$ and $\mathrm{Cl}$, also detected by the XPS, are intrinsic contaminations of the PP material. The deconvolution of the C1s spectra in CNF, as it can be seen in Fig. 5a, yielded peaks at 284.8-285 eV assigned to C-C bonds, peaks at 286-287 eV and at $~ 288$ $\mathrm{eV}$ assigned to $\mathrm{C}-\mathrm{O}$ and to $\mathrm{C}=\mathrm{O}$ bonds, respectively [30-32]. It is noteworthy that the $\pi-\pi^{*}$ satellite peak (291 eV) characteristic of $\mathrm{sp}^{2}$ hybridization of carbon atoms in CNF (Fig. 5a), it does not appear in the C1s spectra recorded for the PP/CNF composites (Fig. 5c). That might be an indication of a strong interaction between PP and CNF, which can quench the $\mathrm{sp}^{2}$ hybridization of carbon.
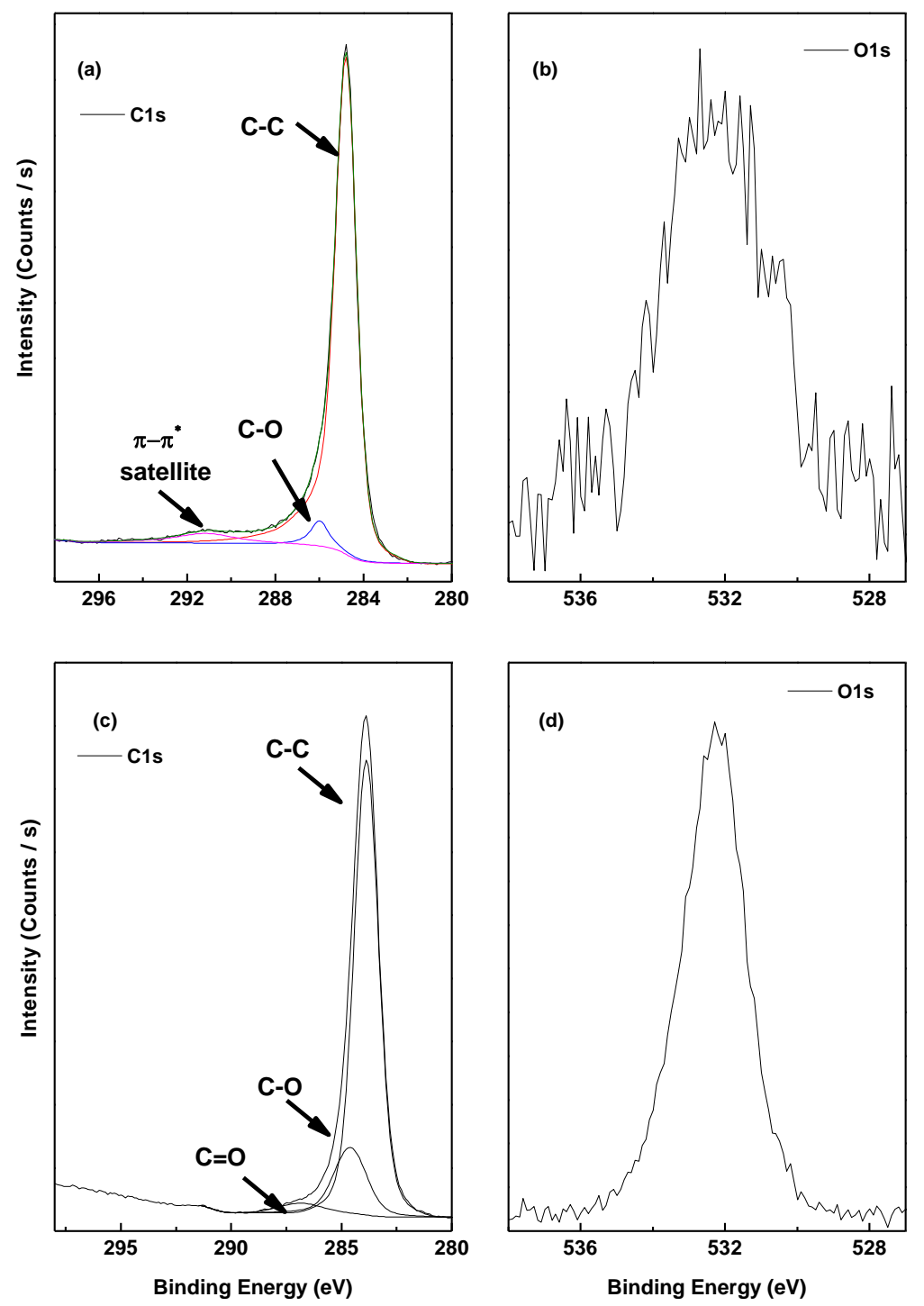

Fig. 5. C1s (a), O1s (b) XPS of PR 24 LHT XT carbon nanofibers and C1s (c), O1s (d) XPS of PP/CNF 2.4 vol\% composites 


\begin{tabular}{cccccccc} 
Sample & O 1s & C 1s & F 1s & Si 2p & N 1s & Na 1s & Cl 2p \\
\hline CNF & 1 & 99 & - & - & - & - & - \\
PP & 11 & 76 & 8 & 4 & 1 & 0.4 & 0.1 \\
PP/CNF 0.4 vol \% & 10 & 83 & 1 & 4 & 1 & 0.7 & 0.5 \\
PP/CNF 1.4 vol \% & 7 & 84 & 5 & 3 & 1 & 0.1 & - \\
PP/CNF 2.4 vol \% & 6 & 87 & 3 & 3 & 1 & 0.2 & 0.1 \\
\hline
\end{tabular}

Table 2. Chemical composition and surface atomic concentrations in $\%$ of CNF, PP and PP/CNF composites obtained from XPS

\subsection{Thermoelectric analysis}

The room-temperature electrical conductivities of the PP/CNF composites as a function of CNF concentration are represented in Fig. 6 (solid symbols). The results show that the conductivity increases as a function of CNF content. A strong increase in conductivity was achieved in PP/CNF composites at 0.4 vol. \% with values of $0.11 \pm 0.02 \mathrm{~S} \mathrm{~m}^{-1}$ when compared to the neat PP $\left(\sim 10^{-12} \mathrm{~S} \mathrm{~m}^{-1}\right)$, whereas the highest electrical conductivity was achieved for composites reinforced with 2.4 vol \% of CNF, which showed a value of $23 \pm 2$ $\mathrm{S} \mathrm{m}^{-1}$. The results show that $\sigma$ can be well described in the framework of the percolation theory. According to that, $\sigma$ obey the power law relationship $\sigma \propto\left(\phi-\phi_{c}\right)^{t}$, for $\phi>\phi_{c}$, where $t$ is a critical exponent, $\phi_{c}$ is the percolation threshold, and $\phi$ is the volume fraction of the filler [33]. It is observed that percolation threshold of PP/CNF composites is bounded between $0 \%$ and 0.4 vol $\%$. A value of $\phi_{c} \sim 0.2$ vol $\%$ can be obtained by fitting the percolation equation with the exponent $t$ was equal to $2.2( \pm 0.3)$, which is fairly good agreement with the percolation theory for 3D systems, where $t$ takes values between 1.6 and 2.0 [34].

The thermoelectric power, at room temperature, is also shown in Fig. 6 (open symbols). In particular, a Seebeck coefficient of $-8.7 \pm 5.4 \mu \mathrm{VK}^{-1}$ is observed for the percolated PP/CNF composites reinforced with 0.4 vol. \% of carbon nanofibers. This value remains practically constant and negative for all studied PP/CNF concentrations. Though it is generally accepted that heterogeneous conducting polymer composites show a linear trend of decreasing $\alpha$ with increasing $\sigma$ caused by the higher contents of CNF introduced in the polymer [35], a constant $\alpha$ has also been observed in percolated conducting polymer 
systems with lower contents of carbon nanostructures as observed in our study [36]. The observed large standard deviation of $\pm 5.4 \mu \mathrm{VK}^{-1}$ for composites with 0.4 vol \% of CNF can be explained by measurement uncertainty due to their relatively low conductivity $(\sigma=$ $0.11 \pm 0.02 \mathrm{~S} \mathrm{~m}^{-1}$ ), two orders of magnitude lower than the observed in the PP/CNF composites with 1.4 vol $\%$ of $\operatorname{CNF}\left(\sigma=11.2 \pm 0.3 \mathrm{~S} \mathrm{~m}^{-1}\right)$. More significant is the negative sign of TEP observed. In this respect, it should be noted that the authors have not found any article reporting n-type TE composites directly obtained by melt or solution mixing an insulating polymer with carbon nanostructures (including CNT, and other 2D carbon nanostructures such as graphene and their derivatives) without using pre-treatment methods of functionalization or some kind of additives during processing [12]. Furthermore, due to the insulating nature of the PP used, it is reasonable to think that the negative Seebeck coefficient is due to the n-type TEP behavior of the CNF used (PR 24 LHT XT, Pyrograf®III). In this regard, the authors have found a previous work reporting negative TEP for chemical vapor deposition MWCNT [11]. In particular, the negative TEP was observed in buckypapers of MWCNT growth by CVD method at temperatures above $770{ }^{\circ} \mathrm{C}$. In their work, comparing MWCNT growth at temperatures above and below $770{ }^{\circ} \mathrm{C}$, Hewitt et al. explain that the negative TEP may be caused by the larger-than-50 nm diameters observed for the CVD MWCNT grown above $770{ }^{\circ} \mathrm{C}$, which increase the number of inner shells surrounding their tubular structure. They conclude that this negative TEP is caused by the intrinsic negative contribution (electron conduction) from the inner shells, which is able to counteract the positive contribution (hole conduction) produced by the surface oxygenation on the outer shells. On the contrary, the CVD MWCNT produced by using temperatures below than $770{ }^{\circ} \mathrm{C}$ showed positive TEP caused by the observed diameters below $50 \mathrm{~nm}$ with lower number of inner shells. Therefore, our results seem to confirm the claims discussed in the work of Hewitt et al. Similarly to the MWCNT used in their study, we found that our carbon nanofibers were grown by CVD in a reactor maintained at near 1100 ${ }^{\circ} \mathrm{C}$ [17], and, as it was previously shown (Fig. 1), they have large diameters of around 125 nm. Furthermore, this particular carbon nanofiber grade has shown a tubular core surrounded by two structurally different inner and outer layers [16]. This could explain the negative sign of TEP found in our CNF. The hypothetical negative contribution from the inner shells of $\mathrm{CNF}$ would counteract the positive contribution from the outer layers 
produced by the oxidized states as confirmed by XPS (Figure 5b). It must also be pointed out that all the studied composites in our work showed TEP values around $-8.5 \mu \mathrm{VK}^{-1}$, which are slightly higher (absolute value) than the $-6 \mu \mathrm{VK}^{-1}$ reported by Hewitt et al. for their CVD grown above $770{ }^{\circ} \mathrm{C}$ MWCNT and lower than the $-11 \mu \mathrm{VK}^{-1}$ reported for CNF grown by means of methane pyrolysis in the presence of $\mathrm{NiO}$ as a catalyst [14]. The highest $\alpha$ in our study (absolute value) showed a value of $-8.8 \pm 0.6 \mu \mathrm{VK}^{-1}$ for PP/CNF composites reinforced with 2.4 vol. \% of carbon nanofibers. Our Seebeck coefficients are far from the already reported melt extruded PP/SWCNT composites with negative TEP of $-56.6 \mu \mathrm{VK}^{-1}$ [12], but in that study, apart from the SWCNT, which is normally more expensive than the CNF used in this study, the authors had to add $10 \mathrm{wt} \%$ of polyethylene glycol (PEG) during extrusion to get their final negative TEP values. Other studies of the melt mixed ptype TE CPC have shown positive TEP values of $10 \mu \mathrm{VK}^{-1}$ [37] and $14 \mu \mathrm{VK}^{-1}$ [38] for poly(vinylidene) fluoride (PVDF)/MWCNT and poly(carbonate) (PC)/MWCNT composites, respectively. Besides, independently of their negative TEP, our values are similar to those obtained by Antar et al. based on melt-processed poly (lactic acid) (PLA) with CNT of $9.5 \mathrm{~nm}$ produced by catalytic carbon vapor deposition (CCVD), where $\alpha$ of 8$9 \mu \mathrm{VK}^{-1}$ for 12 vol \% PLA/CNT composites has been obtained [36].

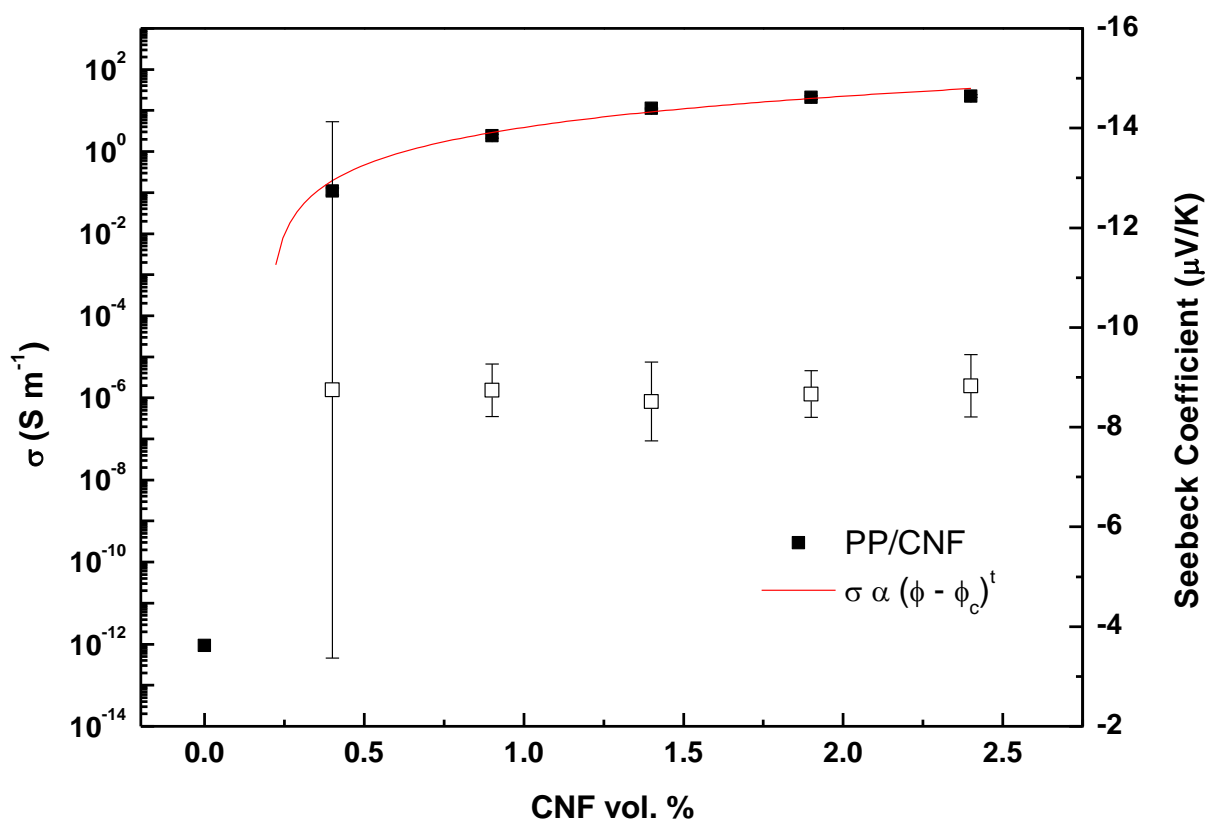


Fig. 6. Electrical conductivity (solid symbols), power law fitting, and negative Seebeck coefficient (open symbols) as function of CNF content in PP/CNF composites

The power factor $\mathrm{PF}\left(\mathrm{S}^{2} \sigma\right)$ of PP/CNF composites at room temperature was also calculated and the results are shown in Fig. 7. As it is observed, the PF increases with the increasing of CNF content. This behavior is mainly due to the increase of $\sigma$ caused by the percolative behavior, since the Seebeck coefficient is almost constant. In fact, the power law $P F \propto$ $\left(\phi-\phi_{c}\right)^{t}$ describes well the variation of PF with CNF content, where $t, \phi_{c}$ and $\phi$, are the same parameters as the ones used in the electrical conductivity discussion. The threshold is located between 0.4 and 0.9 vol. \%, which is indicated by a change of 2 orders of magnitude in their PF. More precisely a value of $\phi_{c}=0.5$ vol. $\%$ was obtained with $t=1.1 \pm$ 0.3. According to these results, PF threshold is higher than the $\sigma$ threshold previously obtained $\left(\phi_{c}=0.23\right.$ vol $\left.\%\right)$, i. e., electrical connectivity between fibers precedes power factor response in these composites. Although the use of the power law is discussed in the literature to calculate intrinsic Seebeck coefficients of MWCNT $\left(12 \mu \mathrm{VK}^{-1}\right)$ and SWCNT (32 $\mu \mathrm{VK}^{-1}$ ) in poly(3-hexylthiophene) (P3HT)/CNT films produced by solution casting [39], we did not find any work which compares electrical and PF thresholds. Finally, the highest power factor, with a value of $1.75 \times 10^{-3} \mu \mathrm{W} \mathrm{m} \mathrm{m}^{-1} \mathrm{~K}^{-2}$, was obtained for composites reinforced with 2.4 vol. \% of $\mathrm{CNF}$, which is comparable with values reported in meltprocessed PP with 0.8 wt \% of CNT [12], but it is very far from PF reported in studies based on solution processed CPC, where values of $1825 \mu \mathrm{W} \mathrm{m}{ }^{-1} \mathrm{~K}^{-2}$ were attained [40]. 


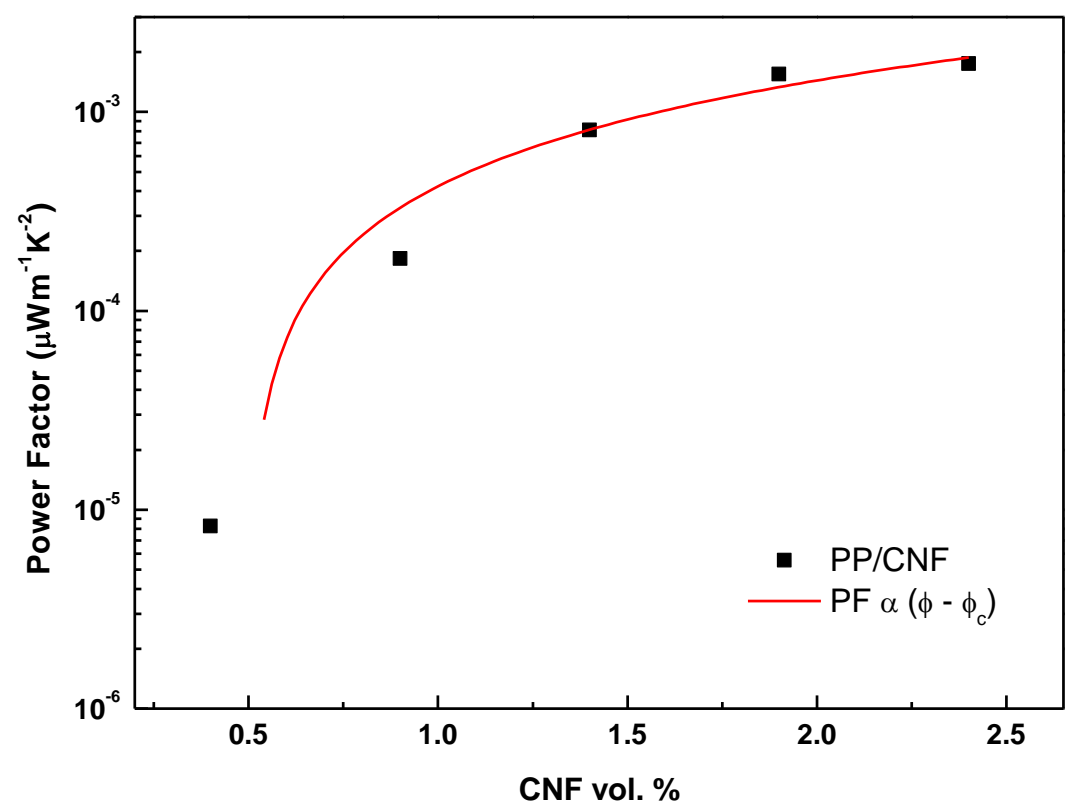

Fig. 7. Power factor as function of CNF contents and corresponding fit with power scaling law of the PP/CNF composites

From the experimental values of electrical conductivity, Seebeck coefficient, and thermal conductivity values shown in Table 3 (measured by using the flash diffusivity method and reported in a previous work for the same PP/CNF composites [41]), the highest figure of merit $z T$ at room temperature for PP composites filled with 2.4 vol. \% of CNF was $4.1 \mathrm{x}$ $10^{-9}$, which is close to the best values of $7.9 \times 10^{-9}$ reported in melt mixed PC filled with functionalized carboxyl MWCNT after addition of cyclic butylene terephthalate (CBT) oligomer [42], four order of magnitude lower than the work based on melt-processed PLA/CNT composites for $18 \mathrm{vol}$. \% of CNT $\left(7 \times 10^{-5}\right)$ [36], and very far from zT reported in studies based on solution mixing $\mathrm{CPC}$, where values of up to 0.25 at room temperature were obtained [43].

\begin{tabular}{cc} 
CNF (vol \%) & Thermal Conductivity (W/mK) \\
\hline 0 & 0.291 \\
0.4 & 0.344 \\
0.9 & 0.337 \\
1.4 & 0.375 \\
1.9 & 0.420 \\
2.4 & 0.437 \\
\hline
\end{tabular}

Table 3. Thermal conductivity of PP/CNF composites [41] 


\section{Conclusions}

Commercial vapor grown carbon nanofibers, produced by chemical vapor deposition, with graphitic tubular cores surrounded by two structurally different inner and outer layers, were melt mixed with polypropylene by twin-screw extrusion. Their morphologic, structural and thermoelectric properties were analyzed. The morphological analysis showed that CNF exhibit good dispersion within the polypropylene. The FTIR spectra of pristine CNF show typical absorption bands associated to the carbon. On the other hand, the Raman spectra of as-produced CNF presents the typical signature expected for $\mathrm{sp}^{2}$ carbon-based materials with only two Raman bands, the D-band assigned to the presence of disorder in graphitic materials, and the G-band characteristic of the ideal graphitic lattice vibration mode. Furthermore, the analysis of pristine CNF by XPS confirmed the presence of oxygenatedfunctional groups appearing on carbon nanofiber surfaces, commonly observed in most of as-produced p-type CNT. The electrical conductivities found for PP/CNF composites with CNF contents from 0.4 to 2.4 vol. \% can be well described in the framework of the percolation theory for 3D systems. All the conducting composites showed negative thermoelectric power values of around $-8.5 \mu \mathrm{VK}^{-1}$. The unexpected negative sign observed can be explained by the large diameter of $125 \mathrm{~nm}$ and double layer structure surrounding the tubular core of $\mathrm{CNF}$ produced by CVD at growth temperature of $1100{ }^{\circ} \mathrm{C}$. The hypothetical negative contribution (electron conduction) from the inner layer would compensate the positive contribution (hole conduction) from the outer shell due to the typical oxygen doping after CNF production. As far as the authors are aware, this is the first work reporting melt compounded polymer composites with large diameter tubular carbon nanostructures and negative TEP values without requiring specific additives and/or deoxygenation treatments.

\section{Acknowledgements}

This work was partly financed by FEDER funds through the Competitivity Factors Operational Programme - COMPETE 2020 and by national funds through FCT Foundation for Science and Technology (project POCI-01-0145-FEDER-007136, POCI01-0145-FEDER-006941 and POCI-01-0145-FEDER-016723 and Strategic Funding UID/FIS/04650/2013 and UID/EEA/04436/2013). E. M. F. Vieira is grateful for financial 
support through the FCT grant SFRH/BPD/95905/2013. A. J. Paleo thanks to Prof. A. I. Pernas from the Group of Polymers of the University of A Coruña for TEM micrographs.

\section{References}

[1] M.V. Vedernikov, E.K. Iordanishvili, A.F.Ioffe and origin of modern semiconductor thermoelectric energy conversion, in: International Conference on Thermoelectrics, ICT, Proceedings, 1998, pp. 37-42.

[2] J.L. Blackburn, A.J. Ferguson, C. Cho, J.C. Grunlan, Carbon-Nanotube-Based Thermoelectric Materials and Devices, Advanced Materials, 30 (2018).

[3] G.J. Snyder, E.S. Toberer, Complex thermoelectric materials, Nature Materials, 7 (2008) 105-114.

[4] D.M. Rowe, CRC Handbook of Thermoelectrics, CRC press, 1995.

[5] Q. Zhang, Y. Sun, W. Xu, D. Zhu, Organic Thermoelectric Materials: Emerging Green Energy Materials Converting Heat to Electricity Directly and Efficiently, Advanced Materials, 26 (2014) 6829-6851.

[6] O.A. Shenderova, V.V. Zhirnov, D.W. Brenner, Carbon Nanostructures, Critical Reviews in Solid State and Materials Sciences, 27 (2002) 227-356.

[7] D. Kang, N. Park, J.H. Ko, E. Bae, W. Park, Oxygen-induced p-type doping of a long individual single-walled carbon nanotube, Nanotechnology, 16 (2005) 1048-1052.

[8] C. Yu, L. Shi, Z. Yao, D. Li, A. Majumdar, Thermal conductance and thermopower of an individual single-wall carbon nanotube, Nano Letters, 5 (2005) 1842-1846.

[9] C.A. Hewitt, A.B. Kaiser, S. Roth, M. Craps, R. Czerw, D.L. Carroll, Varying the concentration of single walled carbon nanotubes in thin film polymer composites, and its effect on thermoelectric power, Applied Physics Letters, 98 (2011).

[10] A. Zettl, Extreme oxygen sensitivity of electronic properties of carbon nanotubes, Science, 287 (2000) 1801-1804.

[11] C.A. Hewitt, A.B. Kaiser, M. Craps, R. Czerw, D.L. Carroll, Negative thermoelectric power from large diameter multiwalled carbon nanotubes grown at high chemical vapor deposition temperatures, Journal of Applied Physics, 114 (2013).

[12] J. Luo, G. Cerretti, B. Krause, L. Zhang, T. Otto, W. Jenschke, M. Ullrich, W. Tremel, B. Voit, P. Pötschke, Polypropylene-based melt mixed composites with singlewalled carbon nanotubes for thermoelectric applications: Switching from p-type to n-type by the addition of polyethylene glycol, Polymer (United Kingdom), 108 (2017) 513-520.

[13] S.A. Gordeyev, F.J. MacEdo, J.A. Ferreira, F.W.J. Van Hattum, C.A. Bernardo, Transport properties of polymer-vapour grown carbon fibre composites, Physica B: Condensed Matter, 279 (2000) 33-36.

[14] I.V. Zolotukhin, I.M. Golev, A.E. Markova, Y.V. Panin, Y.V. Sokolov, A.G. Tkachev, V.L. Negrov, Some properties of solid fractal structures in carbon nanofibers, Technical Physics Letters, 32 (2006) 199-200.

[15] P. Slobodian, P. Riha, R. Olejnik, M. Kovar, P. Svoboda, Thermoelectric properties of carbon nanotube and nanofiber based ethylene-octene copolymer composites for thermoelectric devices, Journal of Nanomaterials, 2013 (2013).

[16] J.P. Tessonnier, D. Rosenthal, T.W. Hansen, C. Hess, M.E. Schuster, R. Blume, F. Girgsdies, N. Pfänder, O. Timpe, D.S. Su, R. Schlögl, Analysis of the structure and 
chemical properties of some commercial carbon nanostructures, Carbon, 47 (2009) 17791798.

[17] G.G. Tibbetts, M.L. Lake, K.L. Strong, B.P. Rice, A review of the fabrication and properties of vapor-grown carbon nanofiber/polymer composites, Composites Science and Technology, 67 (2007) 1709-1718.

[18] A.J. Paleo, V. Sencadas, F.W.J. Van Hattum, S. Lanceros-Méndez, A. Ares, Carbon nanofiber type and content dependence of the physical properties of carbon nanofiber reinforced polypropylene composites, Polym Eng Sci, 54 (2014) 117-128.

[19] A.J. Paleo, A. Zille, F.W. Van Hattum, A. Ares-Pernas, J. Agostinho Moreira, Dielectric relaxation of near-percolated carbon nanofiber polypropylene composites, Physica B: Condensed Matter, 516 (2017) 41-47.

[20] E. Părpăriţă, R.N. Darie, C.M. Popescu, M.A. Uddin, C. Vasile, Structuremorphology-mechanical properties relationship of some polypropylene/lignocellulosic composites, Materials and Design, 56 (2014) 763-772.

[21] A. E., Infrared and Raman spectroscopy of polypropylene., in: K.-K.J. (eds) (Ed.) Polypropylene. Polymer Science and Technology Series, Springer, Dordrecht (1999).

[22] S.N. Arshad, M. Naraghi, I. Chasiotis, Strong carbon nanofibers from electrospun polyacrylonitrile, Carbon, 49 (2011) 1710-1719.

[23] H. Ma, J. Zeng, M.L. Realff, S. Kumar, D.A. Schiraldi, Processing, structure, and properties of fibers from polyester/carbon nanofiber composites, Composites Science and Technology, 63 (2003) 1617-1628.

[24] A.S. Nielsen, R. Pyrz, A Raman study into the effect of transcrystallisation on thermal stresses in embedded single fibres, Journal of Materials Science, 38 (2003) 597-601.

[25] R.G. Snyder, J.H. Schachtschneider, Valence force calculation of the vibrational spectra of crystalline isotactic polypropylene and some deuterated polypropylenes, Spectrochimica Acta, 20 (1964) 853-869.

[26] J.H. Lehman, M. Terrones, E. Mansfield, K.E. Hurst, V. Meunier, Evaluating the characteristics of multiwall carbon nanotubes, Carbon, 49 (2011) 2581-2602.

[27] Y. Wang, D.C. Alsmeyer, R.L. McCreery, Raman Spectroscopy of Carbon Materials: Structural Basis of Observed Spectra, Chemistry of Materials, 2 (1990) 557-563.

[28] A. Ferrari, J. Robertson, Interpretation of Raman spectra of disordered and amorphous carbon, Physical Review B - Condensed Matter and Materials Physics, 61 (2000) 1409514107.

[29] D.S. Knight, W.B. White, Characterization of diamond films by Raman spectroscopy, Journal of Materials Research, 4 (1989) 385-393.

[30] K.L. Klein, A.V. Melechko, T.E. McKnight, S.T. Retterer, P.D. Rack, J.D. Fowlkes, D.C. Joy, M.L. Simpson, Surface characterization and functionalization of carbon nanofibers, Journal of Applied Physics, 103 (2008).

[31] A.B. Dongil, B. Bachiller-Baeza, A. Guerrero-Ruiz, I. Rodríguez-Ramos, A. MartínezAlonso, J.M.D. Tascón, Surface chemical modifications induced on high surface area graphite and carbon nanofibers using different oxidation and functionalization treatments, Journal of Colloid and Interface Science, 355 (2011) 179-189.

[32] J.H. Zhou, Z.J. Sui, J. Zhu, P. Li, D. Chen, Y.C. Dai, W.K. Yuan, Characterization of surface oxygen complexes on carbon nanofibers by TPD, XPS and FT-IR, Carbon, 45 (2007) 785-796. 
[33] D. Stroud, D.J. Bergman, Frequency dependence of the polarization catastrophe at a metal-insulator transition and related problems, Physical Review B, 25 (1982) 2061-2064.

[34] A.J. Paleo, F.W.J. Van Hattum, J. Pereira, J.G. Rocha, J. Silva, V. Sencadas, S. Lanceros-Méndez, The piezoresistive effect in polypropylene-carbon nanofibre composites obtained by shear extrusion, Smart Materials and Structures, 19 (2010).

[35] J. Luo, B. Krause, P. Pötschke, Melt-mixed thermoplastic composites containing carbon nanotubes for thermoelectric applications, AIMS Materials Science, 3 (2016) 11071116.

[36] Z. Antar, J.F. Feller, H. Noël, P. Glouannec, K. Elleuch, Thermoelectric behaviour of melt processed carbon nanotube/graphite/ poly(lactic acid) conductive biopolymer nanocomposites (CPC), Materials Letters, 67 (2012) 210-214.

[37] Y.C. Sun, D. Terakita, A.C. Tseng, H.E. Naguib, Study on the thermoelectric properties of PVDF/MWCNT and PVDF/GNP composite foam, Smart Materials and Structures, 24 (2015).

[38] M. Liebscher, T. Gärtner, L. Tzounis, M. Mičušík, P. Pötschke, M. Stamm, G. Heinrich, B. Voit, Influence of the MWCNT surface functionalization on the thermoelectric properties of melt-mixed polycarbonate composites, Composites Science and Technology, 101 (2014) 133-138.

[39] C. Bounioux, P. Díaz-Chao, M. Campoy-Quiles, M.S. Martín-González, A.R. Goñi, R. Yerushalmi-Rozen, C. Müller, Thermoelectric composites of poly(3-hexylthiophene) and carbon nanotubes with a large power factor, Energy and Environmental Science, 6 (2013) 918-925.

[40] C. Cho, B. Stevens, J.H. Hsu, R. Bureau, D.A. Hagen, O. Regev, C. Yu, J.C. Grunlan, Completely organic multilayer thin film with thermoelectric power factor rivaling inorganic tellurides, Advanced Materials, 27 (2015) 2996-3001.

[41] A.J. Paleo, X. García, L. Arboleda-Clemente, F.W. Van Hattum, M.J. Abad, A. Ares, Enhanced thermal conductivity of rheologically percolated carbon nanofiber reinforced polypropylene composites, Polymers for Advanced Technologies, 26 (2015) 369-375.

[42] L. Tzounis, T. Gärtner, M. Liebscher, P. Pötschke, M. Stamm, B. Voit, G. Heinrich, Influence of a cyclic butylene terephthalate oligomer on the processability and thermoelectric properties of polycarbonate/MWCNT nanocomposites, Polymer (United Kingdom), 55 (2014) 5381-5388.

[43] O. Bubnova, Z.U. Khan, A. Malti, S. Braun, M. Fahlman, M. Berggren, X. Crispin, Optimization of the thermoelectric figure of merit in the conducting polymer poly $(3,4-$ ethylenedioxythiophene), Nature Materials, 10 (2011) 429. 


\section{CARBON submission checklist}

Please check the following points before approving the PDF file for your manuscript. Manuscripts that do not conform may be returned for correction and resubmission. You should be able to answer "yes" to all of the following questions. Items 11 and 14 may not be applicable.

1. Is the manuscript double-spaced or 1.5-spaced with a font size of 12 pt.? (Times or Times New Roman and 1 inch margins are preferred)? Yes, it is.

2. Have you given full addresses and affiliations for all co-authors? Yes, I have.

3. Does the manuscript include a one paragraph abstract of less than 200 words (Review articles and Research papers) or less than 100 words (Letters)? Make sure the abstract is included in the manuscript. For the manuscript of a Letter separate the abstract from the text by an extra line space or a horizontal line. Yes, it does.

4. Is the corresponding author or corresponding authors identified by * and contact details (tel. number and e-mail address) given as a footnote to the first page? Do not include the address, which should be included in the ms heading as part of the author affiliations. Use the following format:

${ }^{*}$ Corresponding author. E-mail: Robert_Hurt@brown.edu (Robert Hurt) Note: Carbon allows more than one corresponding author to be listed on the title page of the manuscript and published article. During submission, however, the electronic system will request a single corresponding author with whom we will communicate during the review purposes. We recommend this author be one of the senior members of the author team.

Yes, it is.

5. Are sections given Arabic numbers with subsections numbered using the decimal system? For example:

\section{Experimental}

2.1 Sample preparation

2.1.1 Sample modification

NOTE: Acknowledgements and References sections are not numbered.

Yes, they are

6. References.

- are they each given a different number? (do not use 14a. b. c etc.)

- do they all include manuscript titles and page spans?

- have you given the first six author names followed by et al.?

- are they archival? "Web pages, private communications, unpublished results, etc. should be given as footnotes."

YES

7. Are all symbols translated correctly in the PDF file? Please double check equations. Yes, they are

8. Have you designated all illustrative items as Figures? "Charts, diagrams, schemes and photographs are all to be referred to in CARBON as Figures". Yes, I have. 
9. Please imbed figures, tables, and captions within the text after they are first introduced in the text and not at the beginning of a section. They do not need to be listed separately at the back of the manuscript. YEs

10. Have you included the carbon in abbreviations (CNT, CNF, MWCNT etc.)?

NOTE: English grammar dictates that the abbreviation must refer to the singular. One does not use the plural noun as an adjective (fiber composites, fruit salad, nanotube dimensions, vegetable soup, etc.) One says "the production of MWCNTs", but "MWCNT production", "MWCNT properties", etc.

Yes, I have.

11. For a Letter to the Editor - is the text, including references, less than five doublespaced pages? Also, are there no more than five figures + tables combined? This is not a letter to the Editor

12. Have you provided a list of names, affiliations, and e-mail addresses for at least three suggested international (at least two countries) peer reviewers? Also have you included a short rationale for each suggested reviewer choice?

Yes, I have.

13. Does your use of abbreviations conform to the following guidelines given in the Editorial in CARBON 44/5?

1. To define an abbreviation, first write the term in full followed by the abbreviation in parentheses. "Xray diffraction (XRD) examination showed that the samples were ....." Do not do the reverse.

2. Never use or define an abbreviation in the manuscript title.

3. Never use abbreviations in the Abstract without defining them, and only define them if they are used later in the Abstract.

4. Define an abbreviation the first time it is used in the text, even though it may also have been necessary to define it in the Abstract.

5. Only define an abbreviation if you are going to use it later.

Yes, I do.

14. If this is a resubmission as a result of comments from the Editor, have you included replies to these comments in your cover letter? Yes, I have. 